Supplement of SOIL, 3, 177-189, 2017

https://doi.org/10.5194/soil-3-177-2017-supplement

C Author(s) 2017. This work is distributed under

the Creative Commons Attribution 3.0 License.

(c) (1)

Supplement of

\title{
Quantitative imaging of the 3-D distribution of cation adsorption sites in undisturbed soil
}

Hannes Keck et al.

Correspondence to: Hannes Keck (hannes.keck@slu.se)

The copyright of individual parts of the supplement might differ from the CC BY 3.0 License. 
Table S1: Average gray values $(\mathrm{GV})$ of the $\mathrm{KCl}$ and $\mathrm{BaCl}_{2}$ solutions of contrast images with different bulk densities (BD) and its effect on the resulting contrast between the $\mathrm{GV}$ of the $\mathrm{BaCl}_{2}$ and the $\mathrm{KCl}$ solutions.

\begin{tabular}{|l|l|l|l|l|l|}
\hline & Air & $\begin{array}{l}\text { BD 1.12 } \mathbf{g ~ c m}^{-3} \\
\text { Silty clay }\end{array}$ & $\begin{array}{l}\text { BD 1.43 } \mathbf{~ c m}^{-3} \\
\text { Silty clay }\end{array}$ & $\begin{array}{l}\text { BD 1.66 } \mathbf{g} \text { cm} \\
\text { Sand }\end{array}$ & units \\
\hline $\mathrm{KCl}$ solution & 16254.30 & 16026.01 & 16184.68 & 15945.33 & $\mathrm{GV}$ \\
\hline $\mathrm{BaCl}_{2}$ solution & 19043.46 & 19063.68 & 19136.38 & 19159.73 & $\mathrm{GV}$ \\
\hline Resulting contrast & 2789.16 & 3037.68 & 2951.70 & 3214.41 & $\mathrm{GV}$ \\
\hline $\begin{array}{l}\text { Difference in contrast } \\
\text { compared to the air } \\
\text { sample }\end{array}$ & 0 & 8.91 & 5.83 & 15.25 & $\%$ \\
\hline
\end{tabular}




\section{Air}

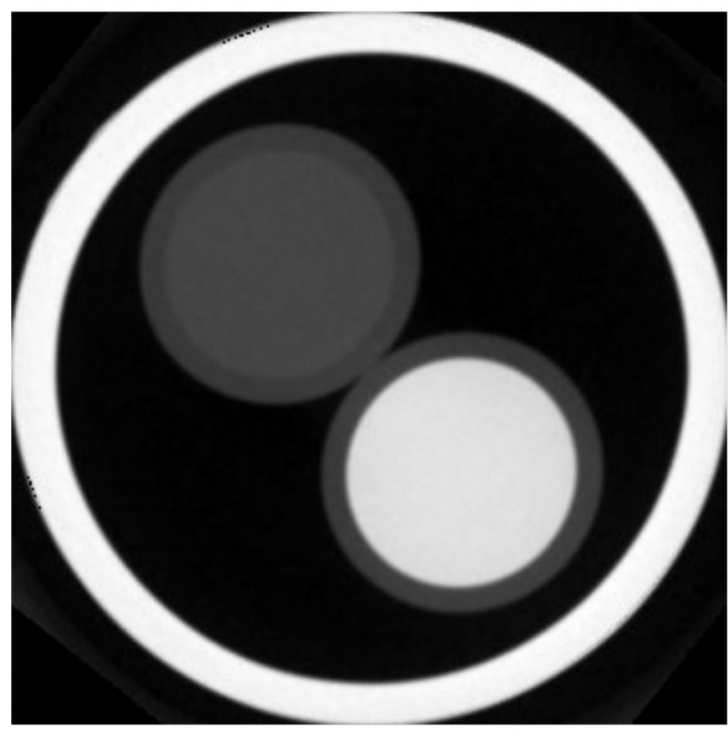

BD $1.43 \mathrm{~g} \mathrm{~cm}^{-3}$

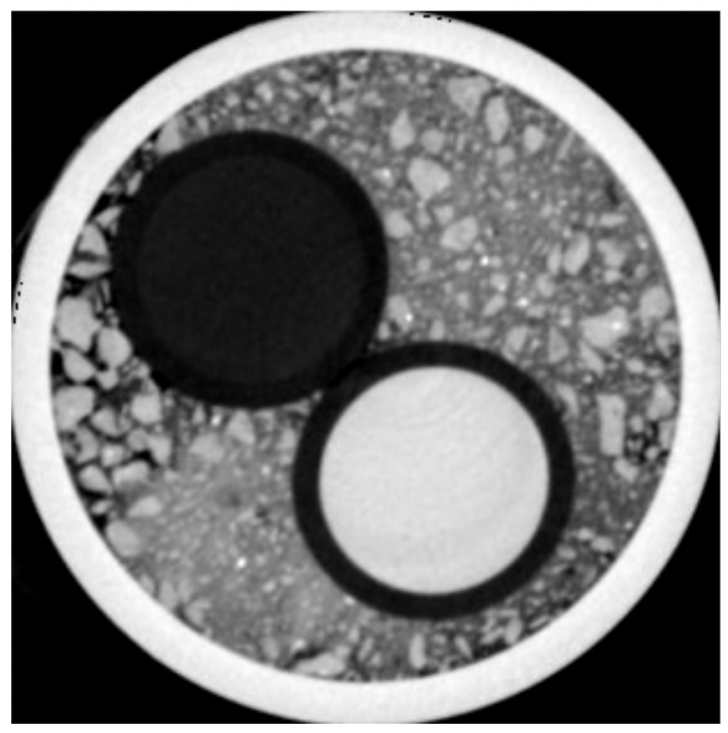

BD $1.12 \mathrm{~g} \mathrm{~cm}^{-3}$

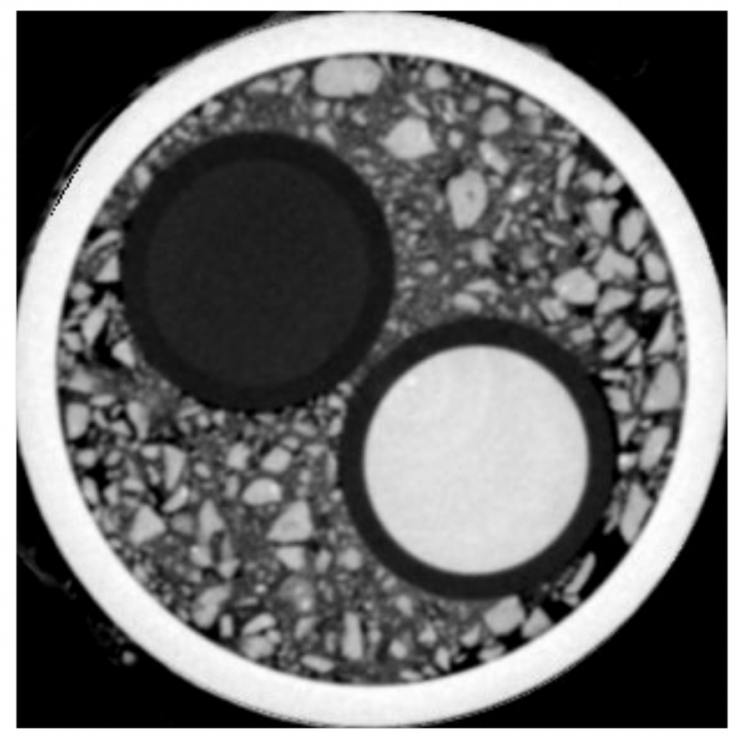

BD $1.66 \mathrm{~g} \mathrm{~cm}^{-3}$

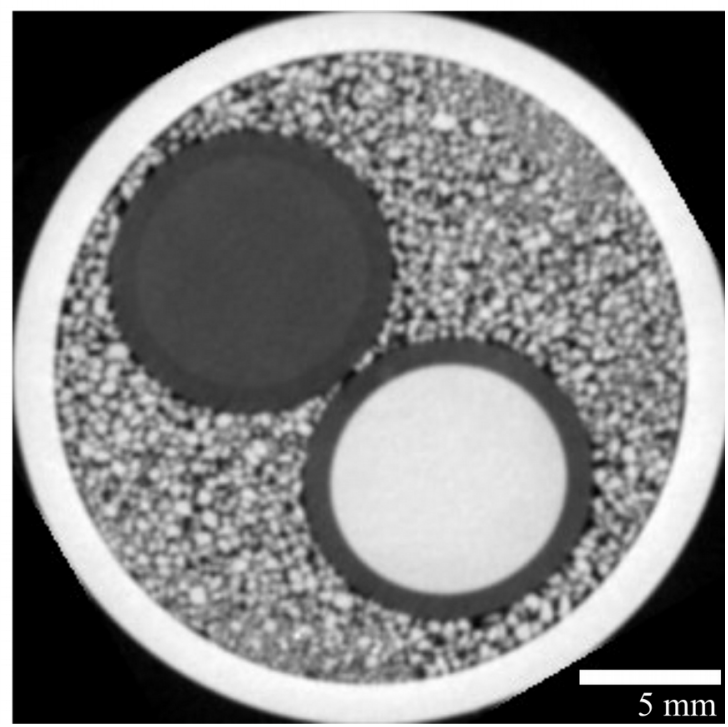

Figure S1. Cross-sections of four different contrast images. 


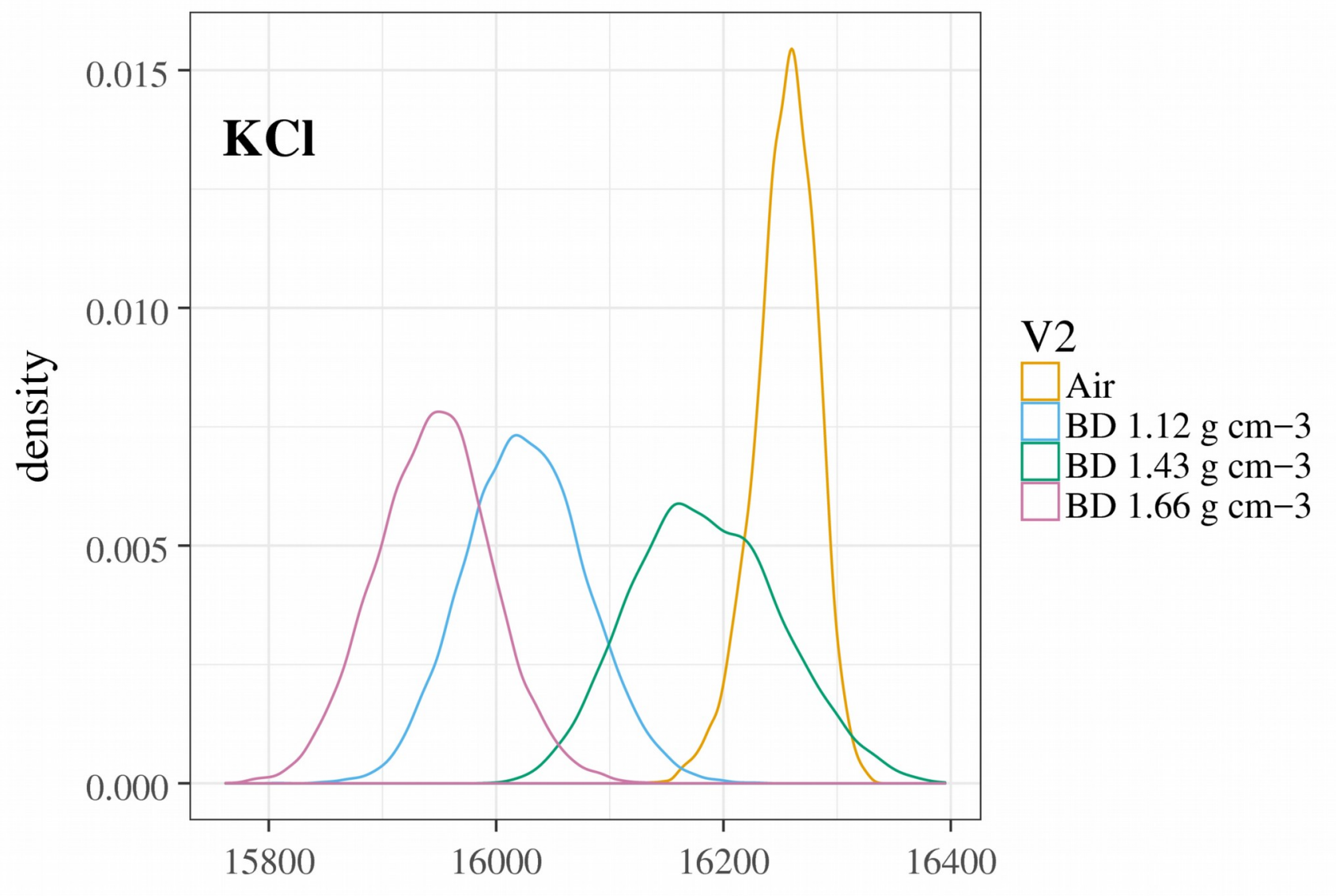

Figure S2: Gray value distributions of the $\mathrm{KCl}$ solution from four different contrast images. Yellow: with an air-filled aluminium column, blue, green and purple: with packed soil but different bulk densities (BD). 


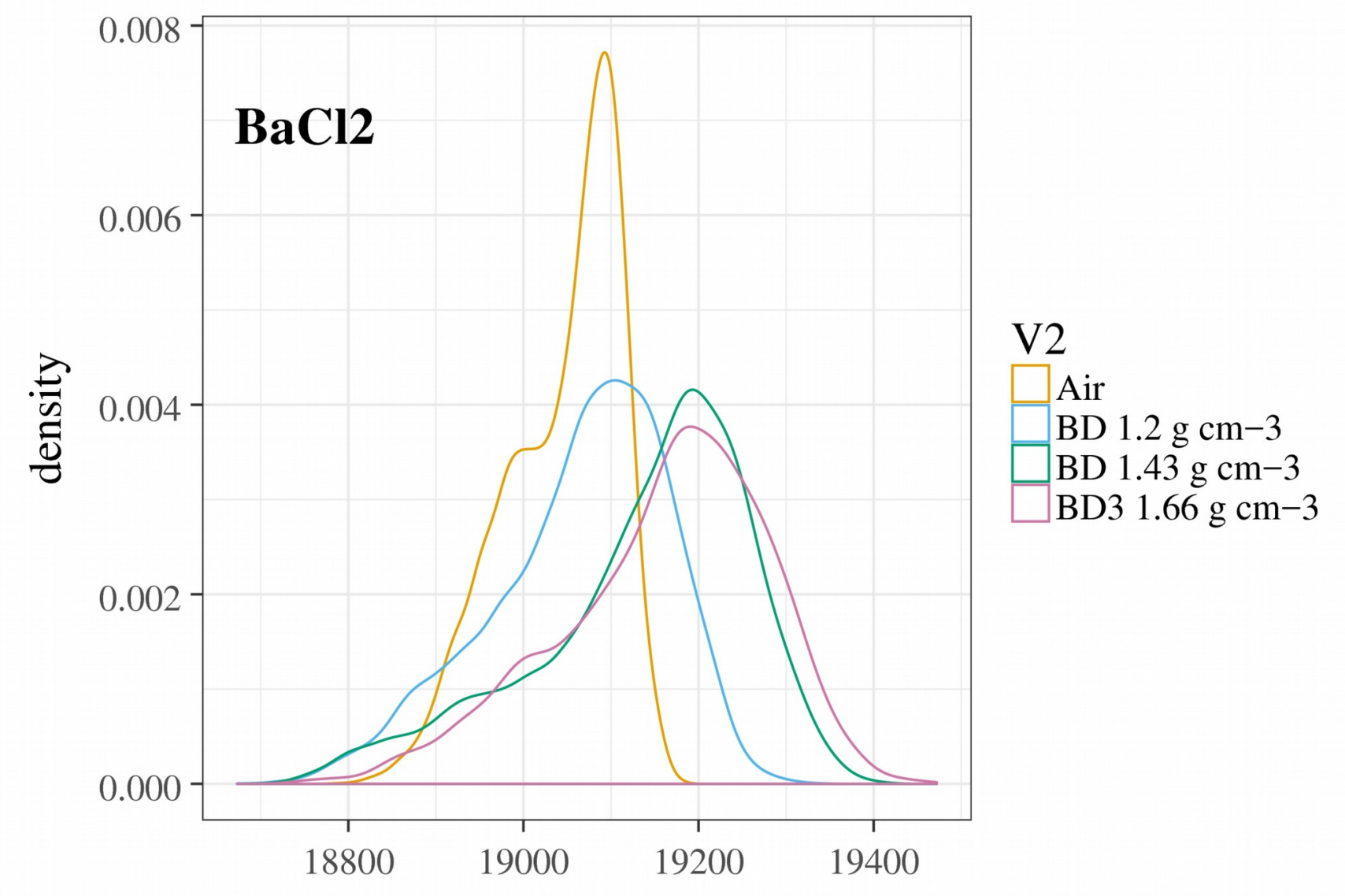

Figure S3: Gray value distributions of the $\mathrm{BaCl}_{2}$ solution from four different contrast images. Yellow: with an air-filled aluminium column, blue, green and purple: with packed soil and different bulk densities (BD). 

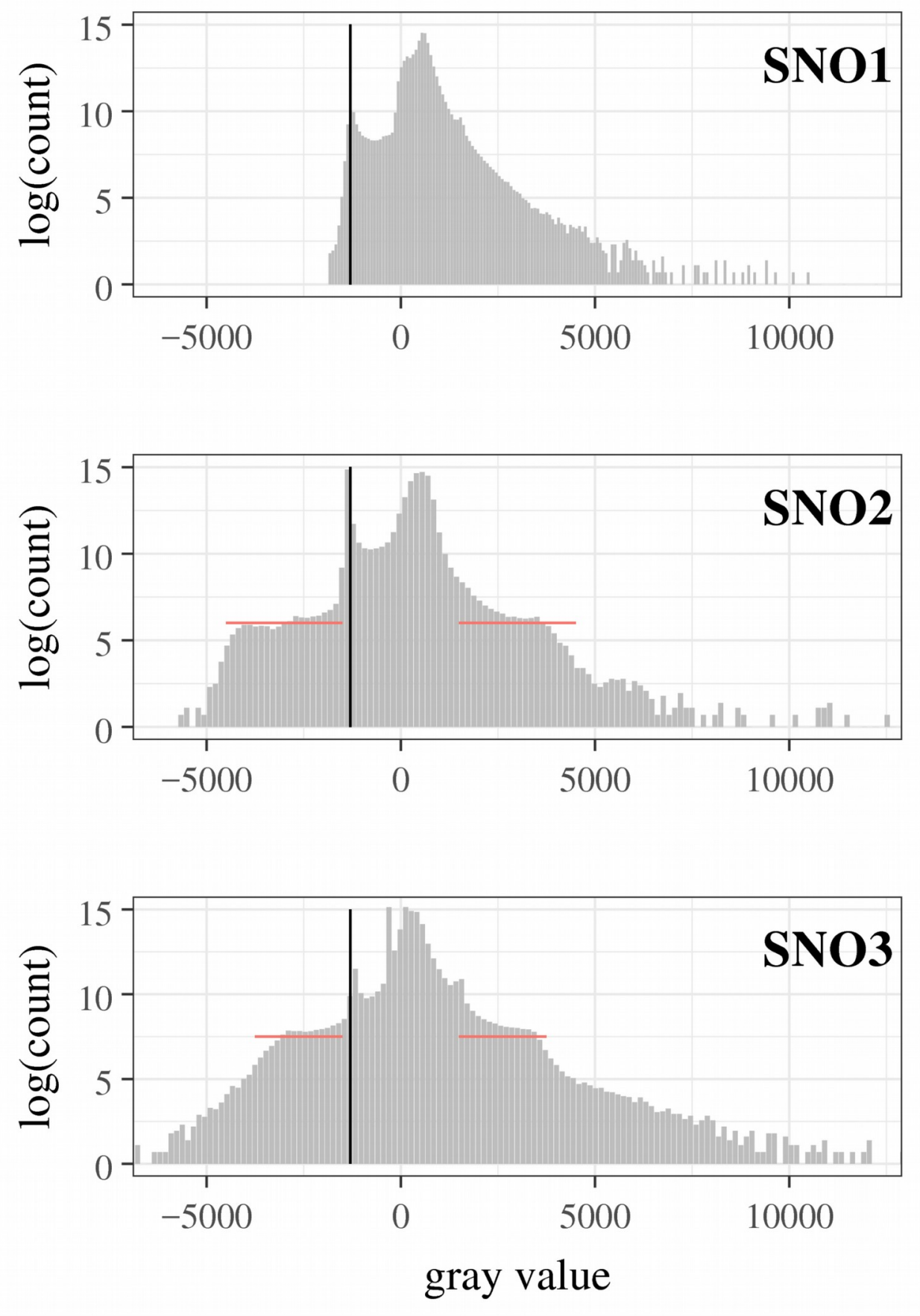

Figure S4: Global gray value distribution for SNO1, SNO2 and SNO3. The horizontal red lines highlight the 'plateau' feature. 


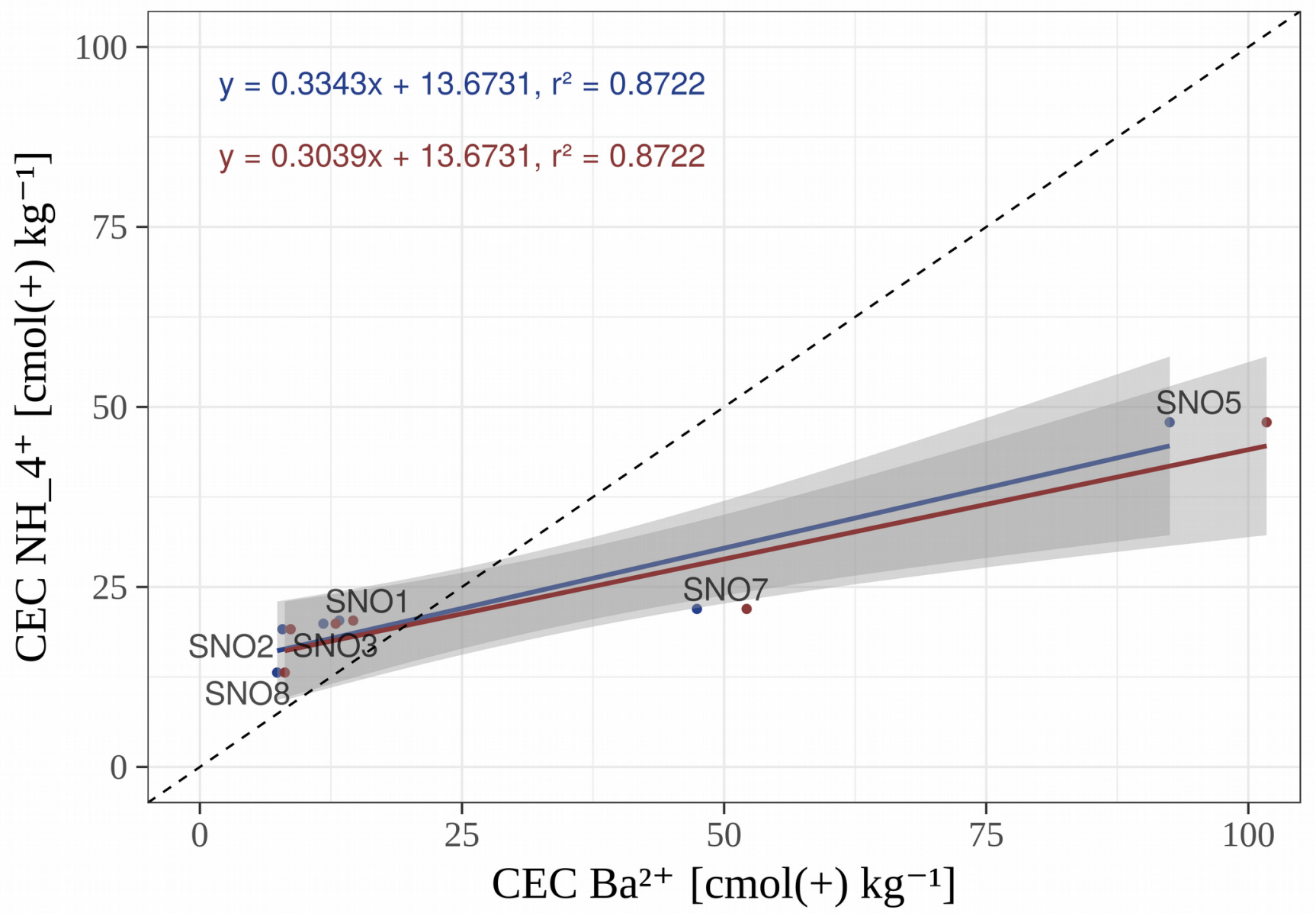

Figure S5. Relation between the cation exchange capacity $\left(\mathrm{cmol}_{(+)} \mathrm{kg}^{-1}\right)$ measured with $\mathrm{NH}_{4}^{+}$and $\mathrm{Ba}^{2+}$ obtained from the difference image analysis of the natural soil samples. Blue represents the original data and red the adjusted data that considers the change in contrasts of the $\mathrm{KCl}$ and $\mathrm{BaCl}_{2}$ solutions as a result of $\mathrm{X}$-ray attenuation by the soil matrix. Blue and red lines represent linear models with $95 \%$ confidence intervals in gray $(\mathrm{p}<0.01)$. The dotted line has a slope of 1 . 